\title{
ANALISA PEMBELIAN KEBUTUHAN PRODUK PENCEGAHAN COVID-I9 OLEH INSTANSI NON PELAYANAN KESEHATAN PADA PT. ERSA PRIMA MEDIKA
}

\section{Purchase Analysis Of Covid-19 Prevention Products By Non Medical Services Institution In PT. Ersa Prima Medika}

\section{A.A Gde Erlangga Kusumaningrat ${ }^{1 *}$}

\section{A.A. Istri Agung Maheswari.S.ST.Par.,M.Par}

\author{
IUniversitas Pendidikan Nasional, \\ Denpasar, Bali, Indonesia \\ 2Universitas Pendidikan Nasional, \\ Denpasar, Bali, Indonesia \\ email:erlanggakusuma3@gmail.com \\ agungmaheswari@undiknas.ac.id
}

\begin{abstract}
Abstrak
Covid-19 merupakan suatu pandemi yang terjadi saat ini di seluruh dunia, tanpa terkecuali di Indonesia. Imbas dari pandemi ini sungguh tidak main - main, banyak perusahaan tutup, pabrik - pabrik bangkrut sampai dengan ekonomipun ikut menciut. Segala kegiatan yang sudah terencana dari jauh haripun ikut digagalkan oleh COVID-19 ini. Sudah hampir 4 bulan lamanya COVID-19 menyerang Indonesia, dimulai pada bulan maret 2020 kasus COVID-19 pertama di Indonesia ditemukan, sejak saat itu pemerintah sudah mulai memperingatkan seluruh warga Indonesia untuk selalu menjaga kesehatan. Sampai dengan pada pertengahan bulan April - Mei kasus positif di Indonesia melonjak tajam dan banyak daerah yang menerapkan Pembatasan Sosial Berskala Besar (PSBB) dan perusahaan - perusahaan tutup sementara dan merumahkan pegawainya. Namun untuk saat ini pemerintah telah menyerukan pola hidup baru yang disebut New Normal atau hidup normal baru yang gunanya untuk menggerakan kembali roda ekonomi masyarakat Indonesia.

Dalam mempersiapkan segala kebutuhan Pencegahan COVID-19, saat ini seluruh instansi yang akan beroperasi kembali maupun yang masih tetap beroperasi saling berbondong - bondong untuk memenuhi kebutuhannya masing - masing, dan tidak jarang beberapa instansi melakukan pembelanjaan kebutuhan new normal dalam jumlah yang sangat besar untuk persediaan selama satu bulan - tiga bulan kedepan. Melihat hal itu, penulis merasa tertarik untuk menganalisa kebutuhan pencegahan COVID-19 apa saja yang dibutuhkan oleh instansi non pelayanan kesehatan dan cara PT. Ersa Prima Medika selaku perusahaan penyedia kebutuhan pencegahan COVID-19 dalam memasarkan produk yang dimiliki.
\end{abstract}

Kata Kunci:

COVID-19

Pandemi

Perusahaan

Normal baru

Kesehatan

\section{Keywords:}

COVID-19

Pandemic

Company

New Normal

Healty

\begin{abstract}
Covid-19 is a pandemic currently occurring throughout the world, without exception in Indonesia. The impact of this pandemic is really no joke, many companies have closed, factories have gone bankrupt and the economy has shrunk too. All activities that have been planned from afar were also thwarted by this COVID-19. It has been almost 4 months since COVID-19 has attacked Indonesia, starting in March 2020 the first case of COVID-19 in Indonesia was discovered, since then the government has started to warn all Indonesians to always maintain their health. Up to mid-April May positive cases in Indonesia jumped sharply and many regions implemented Large-Scale Social Restrictions (PSBB) and companies temporarily closed and laid off their employees. However, for now, the government has called for a new lifestyle called the New Normal or a new normal life, which is used to revive the wheels of the Indonesian economy.

In preparing for all the needs for COVID-19 prevention, currently all agencies that will operate again and those that are still operating have flocked to meet their respective needs, and it is not uncommon for several agencies to spend very large amounts of new normal needs for supplies. for one month - the next three months. Seeing this, the authors are interested in analyzing what COVID-19 prevention needs are needed by non-health service agencies and how PT. Ersa Prima Medika as a provider of COVID-19 prevention needs in marketing its products.
\end{abstract}




\section{PENDAHULUAN}

PT Ersa Prima Medika merupakan perusahaan yang bergerak di bidang penjualan alat kesehatan yang melayani pembelian umum, pembelian rumah sakit sampai dengan pembelian dari instansi pemerintah. Perusahaan yang telah berdiri sejak tahun 1995 ini pertama kali bernama UD Sumber Medika yang bergerak dalam pelayanan pembelian alat kesehatan khusus melayani apotek. Karena meningkatnya kebutuhan akan alat kesehatan dan adanya ketentuan bahwa perusahaan penyalur alat kesehatan harus berstatus PT, maka UD Sumber Medika sejak tahun 2000 berubah nama menjadi PT Ersa Prima medika sehingga dengan perubahan dan adanya ijin sebagai penyalur alat kesehatan, menjadikan PT Ersa Prima Medika terus berkembang dan mulai meneruskan karirnya untuk melayani pembelian barang habis pakai untuk rumah sakit dan sampai dengan tahun 2014 PT Ersa Prima Medika resmi berstatus menjadi distributor utama dengan dipercaya sebagai agen langsung dari beberapa produk ternama seperti OneMed, Solida, Golden Glove dan lain sebagainya.

Pada tahun ini PT Ersa Prima Medika memfokuskan diri untuk melayani seluruh Instansi Pemerintah maupun swasta dalam memenuhi kebutuhan pencegahan COVID-19 sampai dengan kebutuhan New Normal, namun PT Ersa Prima Medika tetap melayani pembelian kebutuhan Rumah Sakit seperti Instrument - Instrument operasi dan lain sebagainya.

\section{METODOLOGI}

Dalam melakukan kegiatan Praktek Kerja Lapangan ini penulis menggunakan sistem wawancara dengan beberapa rekanan perusahaan dan juga dengan melakukan peninjauan langsung kelapangan terkait dengan kebutuhan produk pencegahan COVID-I9. Adapun wawancara dengan beberapa rekanan yang dimaksud adalah wawancara dengan perusahaan lain yang melayani pengadaan produk pencegahan COVID19 pada perusahaan non pelayanan kesehatan. Dan peninjauan langsung yang dimaksud adalah penulis mendatangi beberapa instansi non pelayanan kesehatan secara langsung untuk menawarkan produk dan mengetahui apa saja produk yang dibutuhkan pada instansi tersebut.

\section{HASIL DAN PEMBAHASAN}

Semenjak melayani kebutuhan alat kesehatan di instansi pelayanan kesehatan, PT Ersa Prima Medika memiliki omset rata - rata sebesar Rp. 750.000 .000 perbulan.
Dari seluruh omset tersebut hampir 50\% nya merupakan pembelian barang habis pakai seperti sarung tangan, masker, Spuit, kain kasa, alcohol dan lain sebagainya. Namun dimulai pada bulan Maret 2020, PT Ersa Prima Medika mendapatkan order alat pelindung diri (APD) untuk pertama kalinya. Dikutip dari Kompas.com, kasus positif pertama di Indonesia ditemukan dengan hasil test pada tanggal I Maret 2020 di daerah Depok. Kasus positif pertama ini menimpa warga Negara Indonesia yang berusia 64 tahun dan anaknya yang berusia 3I tahun yang sempar memiliki riwayat kontak fisik dengan warga Negara Jepang yang sempat ke Indonesia.

Pada pertengahan bulan Maret, kasus positif ditemukan di Bali. Semenjak itu permintaan APD di PT Ersa Prima Medika pengalami peningkatan yang sangat tinggi, terbukti dari omset penjualan PT Ersa Prima Medika yang menyentuh angka Rp I.500.000.000 pada bulan Maret 2020. Dari total seluruh omset tersebut $92 \%$ nya adalah penjualan APD dan kebutuhan pencegahan penularan COVID-19. Omset tersebut terus meningkat sampai dengan bulan Mei 2020 ini mendapatkan omset sebesar $\mathrm{Rp}$ 3.000.000.000. dari seluruh omset bulan Mei ini, $90 \%$ nya merupakan alat kebutuhan COVID-19.

Dikutip dari CNNIndonesia.com, Jumat, 15 Mei lalu, Presiden Joko Widodo menyinggung persiapan kondisi tatanan hidup baru (The New Normal) di tengah pandemi Covid-19. Mengikuti seruan tersebut tentunya memberikan angin segar bagi beberapa pelaku usaha untuk memulai kembali pekerjaannaya. Namun pada saat perusahaan akan memulai kembali operasioalnya, haruslah memahami teknis persiapan dalam kondisi tatanan hidup baru. Didalam teknis tersebut berisikan mengenai tata cara menjaga lingkungan seputar kantor sampai dengan menjaga dan memastikan kesehatan dari para pegawai didalam kantor.

Semenjak ditetapkannya persiapan New Normal. PT Ersa Prima Medika banyak menerima pesanan sejumlah alat dan barang pencegahan COVID-19 dari instansi instansi yang bergerak diluar pelayanan kesehatan. Pada pelaporan ini akan menganalisa berbagai kebutuhan apa saja yang dibutuhkan instansi non pelayanan kesehatan untuk menyosong gerakan New Normal dan bagaimana PT Ersa Prima Medika dapat memasarkan dan memenuhi semua produk yang terkait dengan pencegahan COVID-19. 
Dirangkum dari bagian penjualan PT Ersa Prima Medika, nama - nama instansi non pelayanan kesehatan yang membutuhkan produk pencegahan COVID-19 beserta produk yang dibutuhkannya adalah sebagai berikut :

I. Kelurahan Baler Bale Agung Kabupaten Jembrana

TabelI. Kebutuhan produk Kelurahan Baler Bale Agung Kabupaten Jembrana

\begin{tabular}{clcc} 
No & \multicolumn{1}{c}{ Nama Barang } & Volume & Satuan \\
\hline 1 & Thermometer Infrared & 2 & Unit \\
\hline 2 & Hand Sanitizer & 9 & Liter \\
\hline 3 & $\begin{array}{l}\text { Cairan Desinfektan } \\
\text { (Natrium Hipoclorite) }\end{array}$ & 100 & Liter \\
\hline 4 & $\begin{array}{l}\text { Cairan Pembersih } \\
\text { (Lysol) }\end{array}$ & 100 & Liter \\
\hline 5 & Handscone & 15 & Kotak \\
\hline 6 & $\begin{array}{l}\text { Sabun Cuci Tangan } \\
\text { Cair }\end{array}$ & 100 & Liter
\end{tabular}

2. Dinas Pendidikan Kab. Gianyar (TK Negeri

Pembina Tegalalang)

Tabel 2. Kebutuhan Produk Dinas

Pendidikan Kab. Gianyar (TK Negeri Pembina Tegalalang)

\begin{tabular}{clcc} 
No & \multicolumn{1}{c}{ Nama Barang } & Volume & Satuan \\
\hline 1 & $\begin{array}{l}\text { Alat Semprot } \\
\text { Desinfektan }\end{array}$ & 1 & Unit \\
\hline 2 & $\begin{array}{l}\text { Cairan Desinfektan } \\
\text { (Natrium Hipoclorite) }\end{array}$ & 50 & liter
\end{tabular}

3. Dinas Pendidikan Kab. Gianyar (TK Negeri Hindu Kumara Santhi Guwang)

Tabel 3. Kebutuhan Produk Dinas

Pendidikan Kab. Gianyar (TK Negeri Hindu Kumara Santhi Guwang)

\begin{tabular}{clcc} 
No & \multicolumn{1}{c}{ Nama Barang } & Volume & Satuan \\
\hline 1 & $\begin{array}{l}\text { Alat Semprot } \\
\text { Desinfektan }\end{array}$ & 1 & Unit \\
\hline 2 & $\begin{array}{l}\text { Cairan Desinfektan } \\
\text { (Natrium Hipoclorite) }\end{array}$ & 50 & liter \\
\hline 3 & $\begin{array}{l}\text { Wastafel non } \\
\text { permanen }\end{array}$ & 1 & Unit
\end{tabular}

4. Dinas Pendidikan Kab. Gianyar (TK Negeri Hindu Kumara Santhi Guwang)

Tabel 4. Kebutuhan Produk Dinas

Pendidikan Kab. Gianyar (TK Negeri Hindu Kumara Santhi Guwang)

\begin{tabular}{clcc} 
No & \multicolumn{1}{c}{ Nama Barang } & Volume & Satuan \\
\hline 1 & $\begin{array}{l}\text { Alat Semprot } \\
\text { Desinfektan }\end{array}$ & 1 & Unit \\
\hline 2 & $\begin{array}{l}\text { Cairan Desinfektan } \\
\text { (Natrium Hipoclorite) }\end{array}$ & 50 & liter \\
\hline 3 & Wastafel non & 1 & Unit
\end{tabular}

permanen

\begin{tabular}{clcc}
\hline 4 & Thermometer Infrared & 1 & Unit \\
\hline 5 & Handsanitizer $250 \mathrm{ml}$ & 4 & Botol
\end{tabular}

5. Dinas Pendidikan Kab. Gianyar (TK Negeri Pembina Tampak Siring)

Tabel 5. Kebutuhan Produk Dinas Pendidikan Kab. Gianyar (TK Negeri Pembina Tampak Siring)

\begin{tabular}{clcc} 
No & \multicolumn{1}{c}{ Nama Barang } & Volume & Satuan \\
\hline 1 & $\begin{array}{l}\text { Alat Semprot } \\
\text { Desinfektan }\end{array}$ & 1 & Unit \\
\hline 2 & $\begin{array}{l}\text { Cairan Desinfektan } \\
\text { (Natrium Hipoclorite) }\end{array}$ & 50 & liter \\
\hline 3 & Wastafel non permanen & 1 & Unit
\end{tabular}

6. Dinas Pendidikan Kab. Gianyar (TK Negeri Satu Atap Negeri 3 Tulikup)

Tabel 6. Kebutuhan Produk Dinas Pendidikan Kab. Gianyar (TK Negeri Satu Atap Negeri 3 Tulikup)

\begin{tabular}{cccc} 
No & Nama Barang & Volume & Satuan \\
\hline 1 & Wastafel non permanen & 1 & Unit
\end{tabular}

7. Dinas Pendidikan Kab. Gianyar (TK Negeri Hindu Kumara Wiyata)

Tabel 7. Kebutuhan Produk Dinas

Pendidikan Kab. Gianyar (TK Negeri Hindu Kumara Wiyata)

\begin{tabular}{clcc} 
No & \multicolumn{1}{c}{ Nama Barang } & Volume & Satuan \\
\hline 1 & Alat Semprot Desinfektan & 1 & Unit \\
\hline 2 & $\begin{array}{l}\text { Cairan Desinfektan } \\
\text { (Natrium Hipoclorite) }\end{array}$ & 50 & liter \\
\hline 3 & Wastafel non permanen & 1 & Unit
\end{tabular}

8. Dinas Pendidikan Kab. Gianyar (TK Negeri Hindu Tunas Wangi Bona)

Tabel 8. Kebutuhan ProdukDinas Pendidikan Kab. Gianyar (TK Negeri Hindu Tunas Wangi Bona)

\begin{tabular}{clcc} 
No & \multicolumn{1}{c}{ Nama Barang } & Volume & Satuan \\
\hline 1 & $\begin{array}{l}\text { Alat Semprot } \\
\text { Desinfektan }\end{array}$ & 1 & Unit \\
\hline 2 & $\begin{array}{l}\text { Cairan Desinfektan } \\
\text { (Natrium Hipoclorite) }\end{array}$ & 50 & liter \\
\hline 3 & Wastafel non permanen & 1 & Unit
\end{tabular}

9. Dinas Pendidikan Kab. Gianyar (TK Negeri Hindu Widya Kumara)

Tabel 9. Kebutuhan Produk Dinas Pendidikan Kab. Gianyar (TK Negeri Hindu Widya Kumara) 


\begin{tabular}{clcc} 
No & \multicolumn{1}{c}{ Nama Barang } & Volume & Satuan \\
\hline 1 & $\begin{array}{l}\text { Alat Semprot } \\
\text { Desinfektan }\end{array}$ & 1 & Unit \\
\hline 2 & $\begin{array}{l}\text { Cairan Desinfektan } \\
\text { (Natrium Hipoclorite) }\end{array}$ & 50 & liter \\
\hline 3 & $\begin{array}{l}\text { Wastafel non } \\
\text { permanen }\end{array}$ & 1 & Unit
\end{tabular}

10. Dinas Pendidikan Kab. Gianyar (TK Negeri Hindu Widya Craya)

Tabel 10. Kebutuhan Produk Dinas Pendidikan Kab. Gianyar (TK Negeri Hindu Widya Craya)

\begin{tabular}{clcc} 
No & \multicolumn{1}{c}{ Nama Barang } & Volume & Satuan \\
\hline 1 & Alat Semprot Desinfektan & 1 & Unit \\
\hline 2 & $\begin{array}{l}\text { Cairan Desinfektan } \\
\text { (Natrium Hipoclorite) }\end{array}$ & 50 & liter \\
\hline 3 & Wastafel non permanen & 1 & Unit
\end{tabular}

II. Dinas Pendidikan Kab. Gianyar (TK Negeri Hindu Kerta Winangun Santi)

Tabel II. Kebutuhan Produk Dinas Pendidikan Kab. Gianyar (TK Negeri Hindu Kerta Winangun Santi)

\begin{tabular}{clcc} 
No & \multicolumn{1}{c}{ Nama Barang } & Volume & Satuan \\
\hline 1 & Alat Semprot Desinfektan & 1 & Unit \\
\hline 2 & $\begin{array}{l}\text { Cairan Desinfektan } \\
\text { (Natrium Hipoclorite) }\end{array}$ & 50 & liter \\
\hline 3 & Wastafel non permanen & 1 & Unit
\end{tabular}

12. Dinas Pendidikan Kab. Gianyar (TK-SD Satu Atap Negeri I Kenderan)

Tabel 12. Kebutuhan Produk 12. Dinas Pendidikan Kab. Gianyar (TK-SD Satu Atap Negeri I Kenderan)

\begin{tabular}{clcc} 
No & \multicolumn{1}{c}{ Nama Barang } & Volume & Satuan \\
\hline 1 & Alat Semprot Desinfektan & 1 & Unit \\
\hline 2 & $\begin{array}{l}\text { Cairan Desinfektan } \\
\text { (Natrium Hipoclorite) }\end{array}$ & 50 & liter
\end{tabular}

Selain instansi - instansi yang tercantum pada data diatas, PT Ersa Prima Medika juga memiliki rekanan / memiliki kerjasama dengan instansi lain yang bergerak dibidang pengadaan umum seperti UD Gani Prama yang bergerak dibidang perdagangan umum dan juga CV Dana Yudha Karya yang bergerak dibidang kontraktor dan perdagangan umum. Dari 2 instansi tersebut, PT Ersa Prima Medika menjadi distributor dan dijual kembali oleh kedua instansi tersebut.

Berdasarkan data yang didapat dari hasil wawancara dengan kedua instansi tersebut melalui direktur, didapatkan hasil observasi sebagai berikut :

I. Bapak AA Gede Satria (Direktur UD Gani Prama)
Data yang peroleh dari lapangan saat mengobservasi. Yakni: UD Gani Prama sudah berdiri sejak tahun 2015. Dimulai dari menjual segala kebutuhan umum pada instansi intansi seperti kebutuhan ATK, kebutuhan House Keeping sampai dengan kebutuhan praktikum pada sekolah dan perguruan tinggi. Adapun pembicaraan saat wawancara yang dapat penulis kutip yaitu sebagai berikut. "perusahaan yang saya kelola ini memfokuskan diri untuk melayani pengadaan pada instansi non pemerintah saja, karena pada dasarnya instansi non pemerintah tidak memerlukan faktur pajak dan urusan administrasi nya tidak serumit instansi pemerintah. Dari tahun 2015 sampai awal tahun 2020 ini, saya melayani berbagai kebutuhan ATK dan juga peralatan praktikum di instansi swasta dan juga perguruan tinggi swasta. Namun di bulan Maret 2020, seluruh instansi yang menjadi pelanggan saya membatasi pembelian ATK dan sebagainya dikarenakan operasional perusahaan yang berhenti ataupun pembatasan pengeluaran dana. Sehingga dari hal tersebut perusahaan ini sempat mengalami penurunan omset. Saat diumumkannya seluruh instansi / perusahaan akan berjalan normal kembali dengan kebiasaan yang baru. Saya mulai mencari penyalur / distributor alat kesehatan agar dapat menawarkan produk - produk pencegahan COVID kepada pelanggan pelanggan saya, dan hasilnya penjualan alat kebutuhan COVID ini sangat menaikan omset perusahaan. Pada awalnya saya mencari distributor alat kesehatan melalui internet, beberapa distributor saya ada juga dari luar Bali namun karena pengiriman cukup memakan waktu akhirnya saya mencari distributor alat kesehatan yang ada di Bali dan memilih PT Ersa Prima Medika sebagai salah satu distributor alat pencegahan COVID di perusahaan saya. Sampai saat ini pun saya masih rutin mendapatkan order produk habis pakai seperti masker, handsanitizer dan juga desinfektan"

2. Bapak I Wayan Budiastika (Direktur CV Dana Yudha Karya)

Data yang peroleh dari lapangan saat mengobservasi. Yakni : CV Dana Yudha Karya 
berdiri pada tahun 2008 dan bergerak dibidang kontruksi dan focus melayani instansi pemerintah di seluruh bali. Adapun pembicaraan saat wawancara yang dapat penulis kutip yaitu sebagai berikut : "perusahaan yang saya kelola ini telah berdiri dari tahun 2008, pada awalnya perusahaan ini focus pada pelayanan kontruksi untuk instansi pemerintah seperti pembangunan jembatan, pembangunan gedung, irigasi dan jalan. Memasuki tahun 2020 perusahaan ini sudah banyak menerima permintaan untuk melakukan pembangunan jalan ataupun perbaikan jalan. Namun semua proyek tersebut dibatalkan pada bulan maret 2020 saat covid sudah mewabah di provinsi Bali. Dari total sekitar 56 proyek pembangunan pada tahun 2020, hanya 10 proyek saja yang masih berjalan, sisanya ditunda. Adanya penundaan tersebut menjadikan kerugian yang cukup signifikan, karena pada awal tahun saya sudah memesan bahan bahan bangunan seperti semen, batako, genteng dll. Namun karena pembatalan tersebut akhirnya bahan bahan tersebut menjadi stok mengendap di kantor kami, sampai - sampai saya harus menyewa suatu bangunan dekat kantor untuk menyimpan barang - barang tersebut. Setelah mengalami hal tersebut saya pun harus memutar otak agar perusahaan ini tidak jalan ditempat, mengingat harus ada kewajiban kewajiban yang harus saya bayarkan. Akhirnya munculah ide untuk menjual kebutuhan covid19 pada instansi non pelayanan medis, karena kalau masuk kesana harus memiliki izin penyalur alat kesehatan. Akhirnya saya memilih beberapa penyalur alat kesehatan dan menemukan salah satunya kantor PT Ersa Prima Medika ini yang berdomisili di Denpasar. Ternyata setelah saya menjalani pengadaan kebutuhan covid ini, hasilnya sangatlah bagus. Instansi - instansi pemerintah yang saya layani sebelumnya banyak yang memesan kebutuhan pencegahan covid tersebut, seperti masker, handsanitizer, desinfektan dan lain - lain. Perubahan pelayanan pada suatu perusahaan memanglah wajar terjadi, apalagi dimasa seperti ini banyak perusahaan yang banting stir agar tetao dapat bertahan hidup di masa ini. Jika seterusnya ini akan menjanjikan, kelak saya akan membuat suatu usaha lagi dalam hal pengadaan alat kesehatan dan membuat izin penyalur alat kesehatan.

Dalam proses pemasarannya, PT Ersa Prima Medika memiliki 4 orang marketing yang area kerjanya telah dibagi, yaitu area bali bagian utara meliputi Kabupaten Singaraja dan Kabupaten Negara, bagian barat yaitu Kabupaten Tabanan, bagian timur yaitu Kabupaten Karangasem, Kabupaten Klungkung, dan Kabupaten Gianyar dan bagian selatan meliputi Kota Denpasar dan juga Kabupaten Badung. Pada awalnya PT Ersa Prima Medika hanya memasarkan produk - produknya kepada Rumah Sakit, Klinik, Bidan dan juga Dinas kesehatan. Namun untuk saat ini PT Ersa Prima Medika telah menyasar seluruh instansi / perusahaan yang beroperasional dalam keadaan new normal.

\section{KESIMPULAN}

PT Ersa Prima Medika merupakan perusahaan yang bergerak di bidang penjualan alat kesehatan yang melayani pembelian umum, pembelian rumah sakit sampai dengan pembelian dari instansi pemerintah. PT Ersa Prima Medika memiliki omset rata - rata sebesar Rp. 750.000.000 perbulan. Dari seluruh omset tersebut hampir 50\% nya merupakan pembelian barang habis pakai seperti sarung tangan, masker, Spuit, kain kasa, alcohol dan lain sebagainya. Pada pertengahan bulan Maret, kasus positif ditemukan di Bali. Semenjak itu permintaan APD di PT Ersa Prima Medika pengalami peningkatan yang sangat tinggi, terbukti dari omset penjualan PT Ersa Prima Medika yang menyentuh angka Rp I.500.000.000 pada bulan Maret 2020. Dari total seluruh omset tersebut $92 \%$ nya adalah penjualan APD dan kebutuhan pencegahan penularan COVID-19. Omset tersebut terus meningkat sampai dengan bulan Mei 2020 ini mendapatkan omset sebesar $R_{p}$ 3.000.000.000. dari seluruh omset bulan Mei ini, $90 \%$ nya merupakan alat kebutuhan COVID-I9.

Adapun beberapa instansi non pelayanan kesehatan yang rutin membeli produk pencegahan covid-19 adalah : Kelurahan Baler Bale Agung Kabupaten Jembrana, Dinas pendidikan Kabupaten gianyar (yang menaungi TK, SD dan SMP negeri seluruh Kabupaten Gianyar), UD Gani Prama dan CV Dana Yudha Karya. Dari seluruh produk yang dibutuhkan, Handsanitizer dan desinfektan lah yang menjadi produk yang paling sering dicari karena produk tersebut masuk dalam produk habis pakai. 
Dalam mencari beberapa pelanggan baru, PT Ersa Prima Medika memiliki 4 orang marketing yang area kerjanya telah dibagi, yaitu area bali bagian utara meliputi Kabupaten Singaraja dan Kabupaten Negara, bagian barat yaitu Kabupaten Tabanan, bagian timur yaitu Kabupaten Karangasem, Kabupaten Klungkung, dan Kabupaten Gianyar dan bagian selatan meliputi Kota Denpasar dan juga Kabupaten Badung.

\section{UCAPAN TERIMA KASIH}

Ucapan terima kasih dan penghargaan sebesar besarnya penulis berikan kepada PT Ersa Prima Medika selaku tempat pelaksanaan PKL, serta perusahaan UD Gani Prama dan juga CV Dana Yudha Karya yang telah bersedia memberikan jawaban atas pertanyaan dari wawancara tersebut. Tidak lupa pula penulis mengucapkan terimakasih kepada Universitas Pendidikan Nasional Denpasar melalui dosen pembimbing PKL yang telah membimbing penulis sampai dengan penulisan jurnal ini dilakukan.

\section{REFERENSI}

CNNIndonesia. 2020.Hadapi New Normal Saat Kasus Corona

Tak Menentu.https://www.cnnindonesia.com/nasi onal/20200603063534-20-50926 I/jakartahadapi-new-normal-saat-kasus-corona-takmenentu (7 Agustus 2020) 